\title{
CUIDADOS DE ENFERMERÍA EN PACIENTES CON DIABETES MELLITUS TIPO 2 EN TIEMPOS DE PANDEMIA COVID 19
}

\author{
Nursing care in patients with type 2 diabetes mellitus in times of the COVID 19 pandemic
}

\section{Cecilia Teresa Ventura Miranda ${ }^{1, a}$}

${ }^{1}$ Docente asociado de la Facultad de Enfermería, Universidad Nacional San Luis Gonzaga. Ica, Perú.
${ }^{a}$ Doctora en Enfermería.

En el Perú no ha sido ajeno a esta pandemia y existe más de un millón de infectados con más de 50,000 muertos. La gravedad de las complicaciones y los efectos directos o indirectos de la enfermedad con mayores posibilidades en general de infectarse presentando un mayor riesgo de cuadros más graves y una mayor mortalidad.

Mientras no se disponga de estrategias como la buena higiene personal y el distanciamiento social son los enfoques disponibles muy importantes para reducir la transmisión del virus y la mortalidad. No obstante, las acciones de distanciamiento social han interrumpido todas las actividades no esenciales y servicios, tales como comercio, industria, y escuelas siendo una constante la falta de trabajo llevando así el escaso ingreso económico a las familias. Si bien todas estas estrategias son eficaces para detener la propagación del virus, pero estos enfoques producen angustia mental y un estado de vigilia constante.

Debido a esta tensión financiera aguda se producen cambios en la dinámica del hogar en personas enfermas y no enfermas causando así problemas de angustia.

"La COVID-19 y la nueva enfermedad, provocada por el SARS-CoV-2. que ya acumula más de 21 millones de casos y más de dos millones de muertes en todo el mundo, este nuevo coronavirus que es ya la segunda ola tiene una mayor transmisibilidad, y una mayor tasa de mortalidad comparado con otros coronavirus anteriores existentes como el COVID-19 o el MERS-CoV en las personas con diabetes mellitus Tipo 2“ (1), con una enfermedad prevalente estimada de 463 millones de personas a nivel mundial, es uno de los principales factores de riesgo a la COVID-19, y también se ve que la prevalencia a la SARS-CoV-2 en pacientes con diabetes tipo 2 está entre un $9 \%$ y un $14,5 \%(2)$.

Es conocido que la diabetes tipo 2 no aumenta el riesgo de padecer la SARS-CoV2, si esta se encuentra controlada, pero las personas con diabetes tipo 2 que no está controlada presentan mayor riesgo de empeoramiento de la SARS-CoV2 y con síndrome de dificultad respiratoria aguda y sus defensas bajas llegando muy posible a la mortalidad. Es más, se estima que la diabetes tipo 2 supone un riesgo de mortalidad relacionado con el SAR-CoV-2 (1), por ese motivo que es más vulnerables a enfermarse gravemente con el virus COVID-19, debido a las fluctuaciones en los niveles de glucosa en la sangre y, posiblemente, la presencia de complicaciones de la diabetes, que en una persona que no tiene diabetes.

Actualmente, al no disponer de un tratamiento farmacológico ni de una vacuna eficaz contra el SARS-CoV-2, la prevención es la forma más eficaz y acertada que tenemos para controlar la tasa de infección y, por ello es una de las mayores prioridades hoy en día. En este sentido, las tres medidas más importantes e imprescindibles contra el SARS-CoV-2, que en pacientes con diabetes 
cobran doblemente importancia, son el distanciamiento social, el lavado de manos rigurosa, y el uso de mascarilla cubriendo nariz y boca.

Los cuidados de enfermería específicos del paciente con diabetes tipo 2 y el SAR-CoV-2, necesitan una atención especial por parte de los profesionales de enfermería "según la teoría general del cuidado de Dorothea Orem" (3).

Concluyo considerando que se debe de dar atención primaria a la población, potenciando la atención a la salud mental, en la medida en que ha sido un tema que afecta a todo el país. Se debe garantizar las medidas de protección tanto a sanitarios como a pacientes para que se pueda mantener la asistencia a la población.

\section{REFERENCIAS BIBLIOGRÁFICAS.}

1. Ministerio de Salud (MINSA). Coronavirus: detalle sobre las vacunas contra el COVID 19 en el Perú. Lima, Perú, 30 de Abril 2021.

2. Carrillo R, Bernabé A. Diabetes mellitus tipo 2 en Perú, una revisión sistemática sobre la prevalencia e incidencia en la población en general. Salud Publica. Rev. Perú Med Exp Salud Pública ,2019; 36(1): 36-26.

3. Raile M, Marriner A. Modelos y teorías en enfermería. 9ed.Ed. Elsevier España 2014. 